\title{
Aberrant Expression of the Glutamate Transporter Excitatory Amino Acid Transporter 1 (EAAT1) in Alzheimer's Disease
}

\author{
Heather L. Scott, ${ }^{1}$ David V. Pow, ${ }^{2}$ Anthony E. G. Tannenberg, ${ }^{3}$ and Peter R. Dodd ${ }^{1}$ \\ Departments of ${ }^{1}$ Biochemistry and ${ }^{2}$ Physiology and Pharmacology, University of Queensland, Brisbane, Queensland, \\ Australia, 4072, and 'Pathology Department, Mater Misericordiæe Hospital, South Brisbane, Queensland, Australia, 4101
}

\begin{abstract}
Glutamate-mediated toxicity has been implicated in the neurodegeneration observed in Alzheimer's disease. In particular, glutamate transport dysfunction may increase susceptibility to glutamate toxicity, thereby contributing to neuronal cell injury and death. In this study, we examined the cellular localization of the glial glutamate transporter excitatory amino acid transporter 1 (EAAT1) in the cerebral cortex of control, Alzheimer's disease, and non-Alzheimer dementia cases. We found that EAAT1 was strongly expressed in a subset of cortical pyramidal neurons in dementia cases showing Alzheimer-type pathology.
\end{abstract}

A link between glutamate transporter dysfunction, increased extracellular glutamate levels, and onset of excitotoxic neuronal damage has been established in animal models (Rothstein et al., 1996; Rao et al., 2001) and in some human neurodegenerative diseases, such as amyotrophic lateral sclerosis (Rothstein et al., 1992, 1995; Lin et al., 1998). Altered glutamate transport has been implicated in Alzheimer's disease (AD), with biochemical studies showing reduced numbers of high-affinity glutamate uptake sites in AD in many cortical areas and a lower maximal D- $\left[{ }^{3} \mathrm{H}\right]$ aspartate uptake rate (early studies by Cross et al., 1987; Cowburn et al., 1988) (for review, see Scott et al., 1995). Different pharmacological profiles of glutamate transporter sites have also been found in a number of cortical regions in AD cases compared with controls (Dodd et al., 1994).

A number of excitatory amino acid transporters (EAATs) have now been isolated and characterized (for review, see Robinson, 1999). EAAT1 is primarily localized to glia in the cerebellum and retina (Rothstein et al., 1994; Lehre et al., 1995); EAAT2 is specifically located on astrocytes and is quantitatively dominant in cortex (Arriza et al., 1994; Rothstein et al., 1994; Chaudhry et al., 1995; Lehre et al., 1995); EAAT3 has a postsynaptic neuronal localization that includes non-glutamatergic neurons (Rothstein et al., 1994); EAAT4 is located in cerebellar Purkinje cells (Dehnes et al., 1998); and EAAT5 is restricted to photoreceptors in the retina (Pow and Barnett, 2000).

Received May 31, 2001; revised Nov. 9, 2001; accepted Nov. 20, 2001

This work was supported by the Alzheimer's Disease and Related Disorders Association (United States), by the National Health and Medical Research Council (NH\&MRC) Brain Tissue Resource (Australia), and by the NH\&MRC (Australia). We are indebted to the next of kin who gave consent for the use of tissue for research and to the pathologists who performed the autopsies. We thank S. Webb, who facilitated tissue collection, and R. Sullivan and P. Reye for helpful discussions during the course of the research.

Correspondence should be addressed to Dr. H. L. Scott, Department of Biochemistry, University of Queensland, Brisbane, Queensland, Australia, 4072. E-mail: scotth@biosci.uq.edu.au.

Copyright (C) 2002 Society for Neuroscience $\quad 0270-6474 / 02 / 220001-05 \$ 15.00 / 0$
In addition, tau (which is a marker of neurofibrillary pathology) colocalized to those same pyramidal cells that expressed EAAT1. These findings suggest that EAAT1 changes are related to tau expression (and hence neurofibrillary tangle formation) in dementia cases showing Alzheimer-type pathology. This study implicates aberrant glutamate transporter expression as a mechanism involved in neurodegeneration in Alzheimer's disease.

Key words: Alzheimer's disease; glutamate transporter; EAAT1; tau; immunocytochemistry; human cortex

A significant reduction in EAAT2 protein expression levels has been reported in the midfrontal cortex of $\mathrm{AD}$ cases, with no changes observed for EAAT1 or EAAT3 (Li et al., 1997). A separate study found that EAAT1 and EAAT2 expression and protein levels were not correlated with $\mathrm{AD}$ in the cingulate and inferior temporal gyri (Beckstrøm et al., 1999). In a transgenic mouse model expressing the 695 amino acid form of the human amyloid precursor protein with the London mutation (a mutation which occurs in a small percentage of familial AD cases), a reduction in EAAT1 and EAAT2 protein levels in the neocortex was observed (Masliah et al., 2000). The previous AD study (Beckstrøm et al., 1999) and the transgenic mouse study (Masliah et al., 2000) reported light immunolabeling for EAAT1 in pyramidal cells in the cortex, as well as glial labeling.

Because neuronal cells are susceptible to the effects of glutamate toxicity (Choi, 1992), we further explored this finding by examining the cellular localization of EAAT1 in a range of human dementia cases that showed variable pathology, compared with human controls. One of the neuropathological features of $\mathrm{AD}$ is the formation of neurofibrillary tangles (NFTs) within neurons. NFTs contain paired helical filaments composed of the microtubule-associated protein tau in a hyperphosphorylated state (Goedert, 1993). Therefore, tau was used as a marker of damaged neurons to determine whether changes in EAAT1 ex-

This article is published in The Journal of Neuroscience, Rapid Communications Section, which publishes brief, peerreviewed papers online, not in print. Rapid Communications are posted online approximately one month earlier than they would appear if printed. They are listed in the Table of Contents of the next open issue of JNeurosci. Cite this article as: JNeurosci, 2002, 22:RC206 (1-5). The publication date is the date of posting online at www.jneurosci.org.

http://www.jneurosci.org/cgi/content/full/6059 


\begin{tabular}{|c|c|c|c|c|c|}
\hline$\#$ & Age (yr) & $\begin{array}{l}\text { Postmortem } \\
\text { delay (hr) }\end{array}$ & Sex & $\begin{array}{l}\text { Neuropathological } \\
\text { diagnosis }\end{array}$ & Cause of death \\
\hline 1 & 71 & 19.5 & $\mathrm{M}$ & Normal & Perioperative myocardial infarct \\
\hline 2 & 82 & 46.8 & M & Normal & Cardiorespiratory arrest \\
\hline 3 & 57 & 33.7 & $\mathrm{~F}$ & Normal & NA \\
\hline 4 & 66 & 8.7 & M & Normal & Multiple system atrophy \\
\hline 5 & 78 & 4.0 & $\mathrm{~F}$ & Normal & Myocardial infarct \\
\hline 6 & 80 & 24.0 & $\mathrm{~F}$ & $\mathrm{AD}$ & NA \\
\hline 7 & 87 & 35.5 & $\mathrm{~F}$ & $\mathrm{AD}$ & Bowel obstruction \\
\hline 8 & 70 & 9.5 & $\mathrm{~F}$ & $\mathrm{AD}$ & NA \\
\hline 9 & 84 & 24.0 & $\mathrm{M}$ & $\mathrm{AD}$ & Renal failure with oliguria \\
\hline 10 & 61 & 14.8 & $\mathrm{~F}$ & $\mathrm{AD}$ & Chest infection \\
\hline 11 & 77 & 24.0 & $\mathrm{~F}$ & $\mathrm{LBD} / \mathrm{AD}$ & NA \\
\hline 12 & 84 & 41.9 & $\mathrm{~F}$ & $\mathrm{LBD} / \mathrm{AD}$ & Occult carcinoma, AD \\
\hline 13 & 88 & 25.5 & $\mathrm{~F}$ & $\mathrm{LBD} / \mathrm{AD}$ & NA \\
\hline 14 & 80 & 13.5 & $\mathrm{~F}$ & $\mathrm{LBD} / \mathrm{AD}$ & NA \\
\hline 15 & 83 & 38.8 & M & LBD & Pneumonia \\
\hline 16 & 88 & 48.0 & $\mathrm{M}$ & LBD & Left ventricular failure \\
\hline 17 & 75 & 24.0 & $\mathrm{~F}$ & $\mathrm{LBD} / \mathrm{AD} / \mathrm{PD}$ & NA \\
\hline 18 & 79 & 55.3 & $\mathrm{M}$ & Multi-infarct dementia & Cerebrovascular accident \\
\hline
\end{tabular}

M, Male; F, female; LBD, Lewy body disease; PD, Parkinson's disease; NA, not available.

pression could be connected to these cells and thus involved in the process of cell injury. Because the previous studies had only included areas susceptible to damage, we also studied an area that is relatively spared from pathology (i.e., the motor cortex) to determine whether any changes in EAAT1 expression were restricted in their distribution and thus might account for the regional specificity of AD neuropathology. In this study, we show that the glial glutamate transporter EAAT1 is selectively expressed in degenerating neurons and dystrophic neurites in AD cases, and that this altered expression is closely associated with neurofibrillary pathology.

\section{MATERIALS AND METHODS}

Human tissue samples. Brain tissue was obtained at autopsy from a total of 18 patients, including 13 cases diagnosed with dementia and 5 control cases (Table 1). Autopsies were performed by authorized pathologists for confirmation of diagnosis or other clinical imperative; informed consent was obtained from the next of kin in all cases. The control cases did not meet any criteria for a neurological disease either clinically or pathologically. Of the 13 dementia cases, 5 were pathologically diagnosed as AD, 5 showed a combined Lewy body disease and Alzheimer-type pathology, 2 cases were diagnosed as pure Lewy body disease (showing no Alzheimer-type pathology), and 1 case had a diagnosis of multi-infarct dementia (with no Alzheimer-type changes).

Tissue was fixed for $20-24 \mathrm{hr}$ by immersion in $4 \%$ buffered paraformaldehyde at $4^{\circ} \mathrm{C}$ (Pow, 1996), rinsed in $0.1 \mathrm{M} \mathrm{PBS,} \mathrm{pH} \mathrm{7.2,} \mathrm{and} \mathrm{stored} \mathrm{in}$ $0.1 \%$ buffered paraformaldehyde/sodium azide at $4^{\circ} \mathrm{C}$ until use. Samples of the midtemporal gyrus and motor cortex (precentral gyrus) were collected so that an area susceptible to pathological damage (temporal cortex) could be compared with a relatively spared area (motor cortex). "Susceptible" and "spared" areas taken from the same brains served as internal controls, thus reducing confounders such as preterminal medication, agonal factors, and postmortem delay.

Immunocytochemistry. Vibratome sections $(50 \mu \mathrm{m})$ were immunolabeled by a "free-floating" method optimized from standard techniques (Pow, 1996). Four sections were sampled per area for each case. Sections were pretreated in $1 \% \mathrm{H}_{2} \mathrm{O}_{2}$ to remove endogenous peroxidase activity, blocked in $0.5 \%$ bovine serum albumin $/ 0.05 \%$ saponin/PBS, and incubated with primary antibody (diluted in blocking solution). Wellcharacterized polyclonal antibodies directed against EAAT1 that have been raised in rabbits or guinea pigs against either an $\mathrm{N}$-terminal sequence (Pow and Barnett, 1999) or a C-terminal sequence (human sequence 504-519; KNRDVEMGNSVIEENE) by Dr. Pow were used. However, for most of the study, rabbit antiserum to the $\mathrm{N}$ terminus was used. The antibody for tau was a mouse monoclonal antibody obtained commercially from Sigma (Sydney, Australia). Sections were incubated with biotinylated secondary antibody, rinsed, and incubated with streptavidin-biotin horseradish peroxidase (SAB-HRP) complex. After extensive washing in PBS, detection of labeling was by incubation with diaminobenzidine (DAB; $0.2 \mathrm{mg} / \mathrm{ml}$ ) in $\mathrm{PBS}$ and $0.001 \% \mathrm{H}_{2} \mathrm{O}_{2}$.

To define the relationship between glutamate transporter expression and pathological indices of $\mathrm{AD}$, double-labeling studies were required. A sequential double chromagen method for EAAT1 and tau was developed. This method was chosen in preference to immunofluorescence methods because autofluorescence of lipofuscin in human tissues (Dowson and Harris, 1981) makes double-fluorescence immunolabeling studies ambiguous in their interpretation. After pretreatment with $\mathrm{H}_{2} \mathrm{O}_{2}$ and blocking, sections were incubated with the two primary antibodies (against EAAT1 and tau) simultaneously. Sections were then incubated with species-specific secondary antibodies that recognized the two different primary antibodies. An alkaline phosphatase-coupled anti-rabbit secondary antibody was used for the EAAT1 antibody, whereas an anti-mouse biotinylated secondary antibody was used for tau. The sections were then incubated with SAB-HRP complex (for completion of the avidin-biotin complex method that was used for detection of tau; no tertiary amplification step was required for the alkaline phosphatase substrate method used for EAAT1).

After extensive washing in $0.1 \mathrm{~m}$ Tris buffer, $\mathrm{pH}$ 7.4, the alkaline phosphatase-conjugated secondary antibody (that marks labeling for EAAT1) was detected first using the red chromagen Fast Red. Sigma FAST (Fast Red TR/Napthol AS-MIX Alkaline Phosphatase Substrate Tablet Sets) was used as per the manufacturer's instructions. Sections were washed in PBS, followed by detection of the next secondary antibody using the avidin-biotin horseradish peroxidase technique with the chromagen DAB in the presence of $0.001 \% \mathrm{H}_{2} \mathrm{O}_{2}$ and nickel ions $(0.02 \%$ nickel ammonium sulfate). This gave rise to a black reaction product. By documenting all red-stained cells before the second immunostaining step through photography or with a camera lucida, it was possible to demonstrate double labeling, even when labeling of the two chromogens was associated with the same cells. For all immunocytochemical methods, sections from susceptible and spared areas from control and dementia brains were processed in batches to achieve consistent immunostaining and to allow qualitative comparisons between cases.

Controls were performed to confirm that the secondary antibodies did not bind to the inappropriate primary antibodies in the double-labeling experiments. Exclusion of either the EAAT1 or the tau primary antibody 

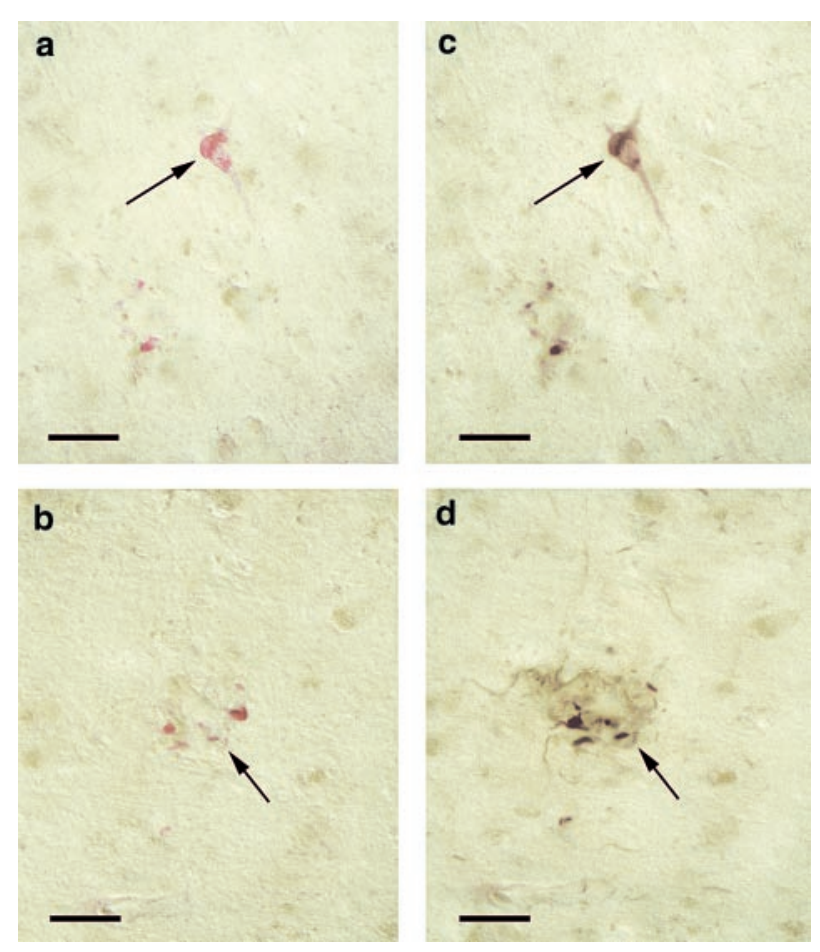

Figure 1. Colocalization of immunostaining for EAAT1 and tau antibodies in neurons and dystrophic neurites. $a$, $c$, Labeling of a pyramidal neuron (arrows) in the midtemporal cortex. $a$, Immunostaining with EAAT1 antibodies. $c$, Subsequent double-immunostaining of the same neuron with tau antibodies. $b, d$, Labeling of neurons and dystrophic neurites (arrows) in the midtemporal cortex. $b$, Immunostaining with EAAT1 antibodies. $d$, Subsequent double-immunostaining with tau antibodies labels the same structures. Scale bars, $20 \mu \mathrm{m}$.

while treating the tissue with both secondary antibodies and processing as above resulted in labeling only for EAAT1 or tau as appropriate.

Materials. The secondary antibodies and streptavidin-biotin horseradish peroxidase complex were obtained from Amersham Biosciences (Sydney, Australia). All other chemicals were obtained from BDH Chemicals (Kilsyth, Australia) or Sigma and were of analytical grade.

\section{RESULTS}

The cellular localization of EAAT1 and tau was examined by immunocytochemical techniques. In the midtemporal cortex, EAAT1 labeling (using the N-terminal antibody) occurred in a distinct proportion of neuronal cells in all AD cases and cases with combined AD and Lewy body disease pathology (i.e., 10 of the 18 cases studied). This labeling was primarily in pyramidal neurons in cortical layers III and IV (Fig. 1a). Dystrophic neurites also labeled for EAAT1 in association with structures that appeared to represent senile plaques in cases showing Alzheimertype pathology (Fig. 1b). Numerous immunolabeled cells were observed in AD cases, with the numbers generally reflecting the degree of neuropathology observed (Fig. 2a). The remaining cases (i.e., the controls and dementia cases showing no Alzheimer-type pathology) showed no or extremely rare EAAT1-positive cells in the midtemporal cortex (Fig. 2b). Glial staining of EAAT1 was not conspicuous in any case.

The motor cortex, which is generally an area that is relatively free of pathological changes in AD, showed varied results. Modest staining of pyramidal neurons for EAAT1 was observed in all AD cases and one combined Lewy body disease/AD case (i.e., 6 of the 18 cases). Some cases had a few EAAT1-positive neuronal cells, whereas other cases had numerous labeled cells. The re-
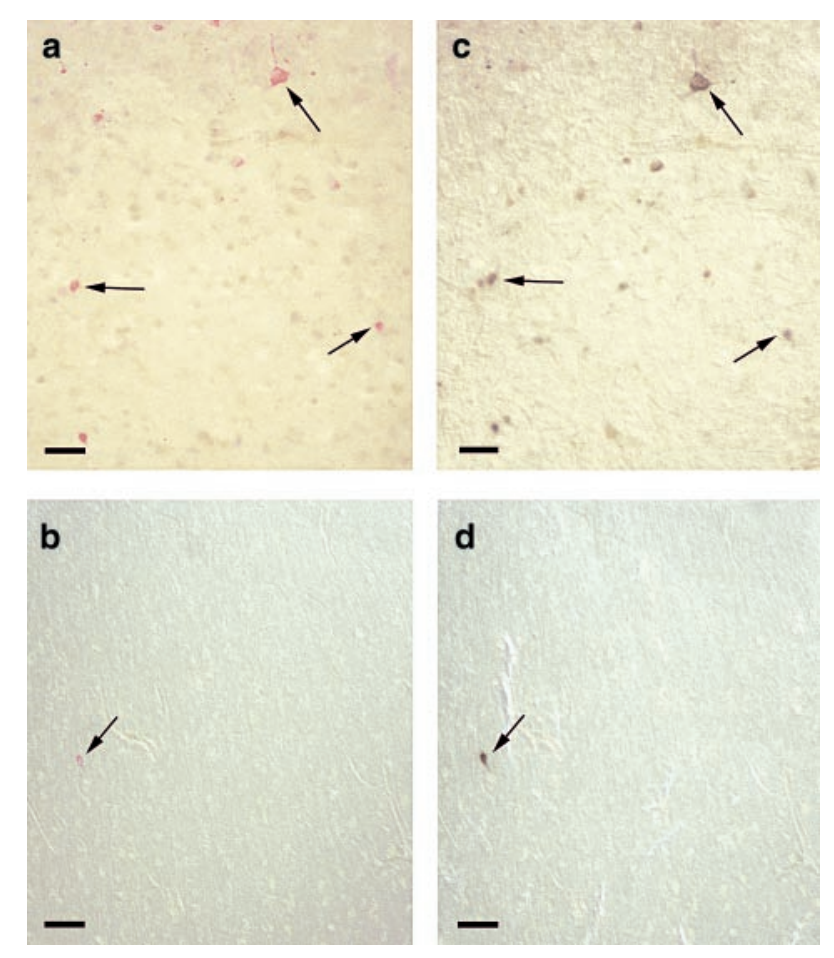

Figure 2. Localization of EAAT1 and tau expression in pyramidal neurons in control and $\mathrm{AD}$ cases. $a, c$, The midtemporal cortex of $\mathrm{AD}$ cases showed numerous EAAT1/tau-positive neurons (arrows indicate some labeled neurons). $a$, Labeling for EAAT1. $c$, Subsequent double labeling with tau antibodies; tau was observed in the EAAT1-positive cells only. $b, d$, The midtemporal cortex of control cases showed no or extremely rare EAAT1/tau-positive cells (arrows). $b$, Immunostaining with EAAT1. $d$, Double-labeling of EAAT1-positive cells with tau. Scale bars, $20 \mu \mathrm{m}$.

maining cases showed no EAAT1-positive cells in the motor cortex. Labeling for EAAT1 and tau was not observed in the large Betz cells of the motor cortex (data not shown). No glial staining was conspicuous in any case.

EAAT1 labeling could be blocked by preincubation with both $10 \mu \mathrm{g} / \mathrm{ml}$ and $100 \mu \mathrm{g} / \mathrm{ml}$ peptide for the N-terminal antibody raised in rabbit. The specificity of the results was examined using additional antibodies for EAAT1. Similar aberrant expression of EAAT1 was shown by both the C-terminal antibody raised in rabbit (Fig. $3 a$ ) and the N-terminal antibody raised in guinea pig (Fig. 3b).

We tested whether these changes could be related to a pathological marker of $\mathrm{AD}$ by using a sequential doubleimmunolabeling technique to determine the colocalization of EAAT1 and tau. In all cases, tau colocalized with EAAT1 (i.e., every cell that stained for tau also stained for EAAT1). This colocalization occurred in the neurons, in dystrophic neurites (Figs. $1 c, d, 2 c, d$ ), and in both cortical regions. However, we found occasional EAAT1-positive cells that exhibited no tau labeling (Fig. 4).

\section{DISCUSSION}

These data suggest that there is abnormal expression of EAAT1 under certain circumstances in human cortex. In cases showing Alzheimer-type neuropathology, EAAT1 was expressed in neurons, primarily a subset of pyramidal cells, and in dystrophic neurites. This aberrant expression was closely associated with tau deposition and hence neurofibrillary changes. The inclusion of 
Figure 3. Localization of EAAT1 expression using alternative antibodies. $a$, Pyramidal neurons (arrow) and dystrophic neurites (asterisk) labeled using an antibody to the C terminus of EAAT1 (raised in rabbit). $b$, A pyramidal neuron (arrow) labeled using an antibody to the $\mathrm{N}$ terminus of EAAT1 (raised in guinea pig). Scale bars, $20 \mu \mathrm{m}$.
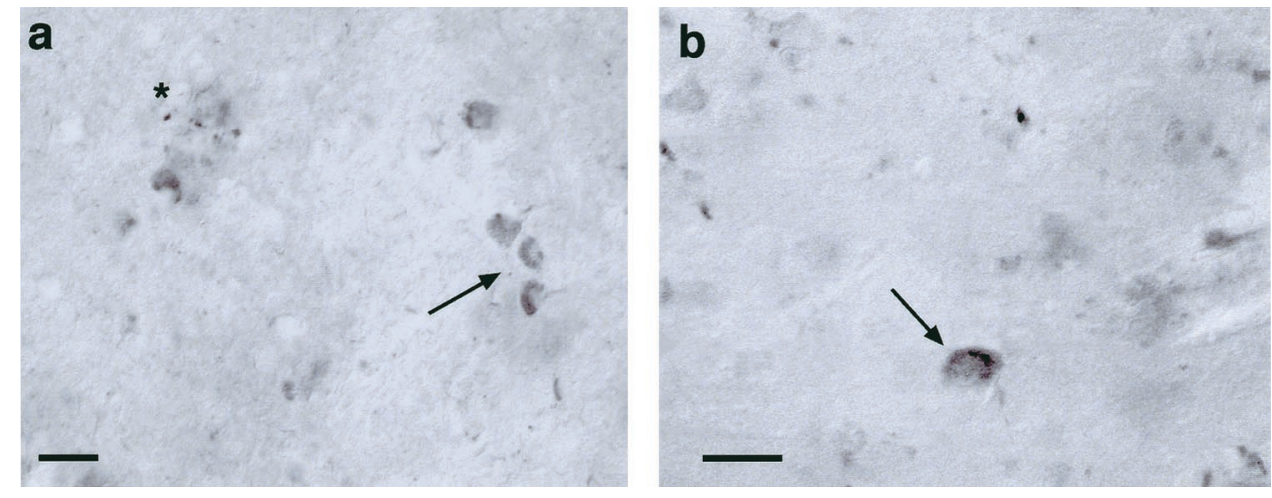
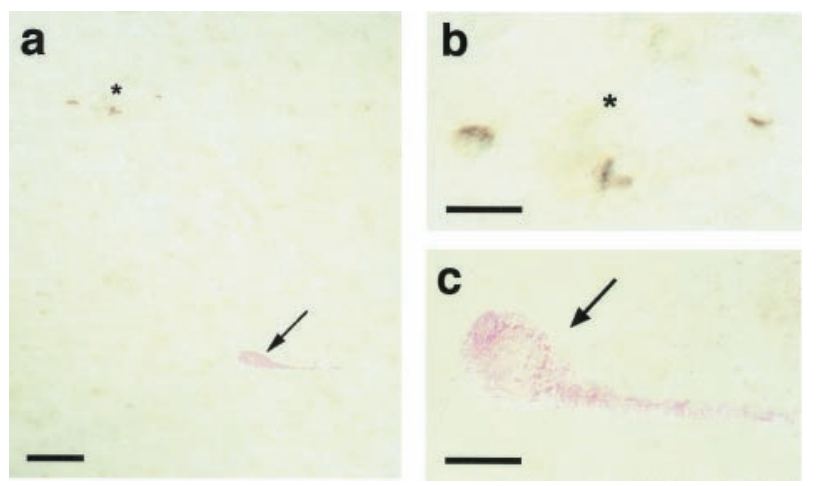

Figure 4. Occasional neurons labeled for EAAT1 but not for tau. $a$, Immunostaining with EAAT1 antibodies showed labeling of some neurons, but subsequent double-immunostaining showed no tau labeling in one EAAT1-positive neuron (arrow) but labeling for tau in other EAAT1positive neurons (asterisk). Scale bar, $20 \mu \mathrm{m}$. b. Inset of neurons labeled for both EAAT1 and tau. Scale bar, $10 \mu \mathrm{m}$. $c$, Inset of a pyramidal neuron labeled for EAAT1 but not tau. Scale bar, $10 \mu \mathrm{m}$.

cases that did not have Alzheimer-type pathology (i.e., controls, cases with pure Lewy body disease, and a dementia case with infarct pathology) confirmed that these changes in EAAT1 expression were specific to cases showing neurofibrillary pathology.

Previous studies have found no difference in EAAT1 protein levels between AD and control cases (Li et al., 1997; Beckstrøm et al., 1999), with a slightly lower, but not significant, EAAT1 immunoreactivity in the AD inferior temporal cortex (Beckstrøm et al., 1999). Our study would suggest an increase in EAAT1 protein levels in the midtemporal cortex of dementia cases showing Alzheimer-type pathology. This could be attributable to the different area studied or to different treatment of the tissue. [One of the previous studies used fresh, frozen tissue sections (Beckstrøm et al., 1999) rather than fixed tissue.] Although one study did show light labeling for EAAT1 in pyramidal cells, the authors did not comment on the level of labeling for EAAT1 between AD and control cases (Li et al., 1997).

Postmortem delay proteolysis of these proteins (EAAT1 and EAAT2) has been shown to be fairly rapid in rat brain tissue, with immunoreactivity being stable for the first $12 \mathrm{hr}$ of storage at room temperature and reducing significantly after that (Beckstrøm et al., 1999). In our human cases, postmortem proteolysis did not seem to be a problem, and we could detect strong immunoreactivity up to at least $55 \mathrm{hr}$ postmortem.

These observations, along with the finding that a few cells that stained for EAAT1 did not stain for tau, whereas all tau-positive cells were also EAAT1-positive, implicates abnormal glutamate transporter expression in the pathology of AD. The expression of a glutamate transporter not normally found in neurons could imply that (1) abnormal EAAT1 expression precedes, and leads to, tangle formation in affected neurons; (2) the expression of EAAT1 is a mechanism to control or prevent excitotoxic damage if increased concentrations of glutamate are present in the extracellular space, and occurs either in addition to normal glial cell function or to replace glial cell function if this is impaired; or (3) the abnormal EAAT1 expression is a result of the pathology already induced within the cell (e.g., by hyperphosphorylation of tau or increased calcium concentrations). The observation that some cells labeled for EAAT1 but not tau suggests that abnormal EAAT1 expression precedes the tau labeling.

We conclude that glutamate transport is altered in dementia cases showing Alzheimer-type pathology, with aberrant expression of EAAT1, and that these changes occur before, but are related to, neurofibrillary pathology. These findings strongly implicate glutamate-mediated toxicity as an important mechanism involved in the neurodegeneration observed in $\mathrm{AD}$.

\section{REFERENCES}

Arriza JL, Fairman WA, Wadiche JI, Murdoch GH, Kavanaugh MP, Amara SG (1994) Functional comparisons of three glutamate transporter subtypes cloned from human motor cortex. J Neurosci 14:5559-5569.

Beckstrøm H, Julsrud L, Haugeto O, Dewar D, Graham DI, Lehre KP, Storm-Mathisen J, Danbolt NC (1999) Interindividual differences in the levels of the glutamate transporters GLAST and GLT, but no clear correlation with Alzheimer's disease. J Neurosci Res 55:218-229.

Chaudhry FA, Lehre KP, van Lookeren Campagne M, Ottersen OP, Danbolt NC, Storm-Mathisen J (1995) Glutamate transporters in glial plasma membranes: highly differentiated localizations revealed by quantitative ultrastructural immunocytochemistry. Neuron 15:711-720.

Choi D (1992) Excitotoxic cell death. J Neurobiol 23:1261-1276.

Cowburn R, Hardy J, Roberts P, Briggs R (1988) Regional distribution of pre- and postsynaptic glutamatergic function in Alzheimer's disease. Brain Res 452:403-407.

Cross A, Slater P, Simpson M, Royston C, Deakin J, Perry R, Perry E (1987) Sodium-dependent $\mathrm{D}-\left[{ }^{3} \mathrm{H}\right]$ aspartate binding in cerebral cortex in patients with Alzheimer's and Parkinson's disease. Neurosci Lett 79:213-217.

Dehnes Y, Chaudhry FA, Ullensvang K, Lehre KP, Storm-Mathisen J, Danbolt NC (1998) The glutamate transporter EAAT4 in rat cerebellar Purkinje cells: a glutamate-gated chloride channel concentrated near the synapse in parts of the dendritic membrane facing astroglia. J Neurosci 18:3606-3619.

Dodd PR, Scott HL, Westphalen RI (1994) Excitotoxic mechanisms in the pathogenesis of dementia. Neurochem Int 25:203-219.

Dowson JH, Harris SJ (1981) Quantitative studies of the autofluorescence derived from neuronal lipof uscin. J Microsc 123:249-258.

Goedert M (1993) Tau protein and the neurofibrillary pathology of Alzheimer's disease. Trends Neurosci 16:460-465.

Lehre KP, Levy LM, Ottersen OP, Storm-Mathisen J, Danbolt NC (1995) Differential expression of two glial glutamate transporters in the rat brain: quantitative and immunocytochemical observations. J Neurosci 15:1835-1853.

Li S, Mallory M, Alford M, Tanaka S, Masliah E (1997) Glutamate transporter alterations in Alzheimer disease are possibly associated with abnormal APP expression. J Neuropathol Exp Neurol 56:901-911. 
Lin C-LG, Bristol LA, Jin L, Dykes-Hoberg M, Crawford T, Clawson L, Rothstein JD (1998) Aberrant RNA processing in a neurodegenerative disease: the cause for absent EAAT2, a glutamate transporter, in amyotrophic lateral sclerosis. Neuron 20:589-602.

Masliah E, Alford M, Mallory M, Rockenstein E, Moechars D, Van Leuven F (2000) Abnormal glutamate transport function in mutant amyloid precursor protein transgenic mice. Exp Neurol 163:381-387.

Pow DV (1996) Immunocytochemical detection of amino acid neurotransmitters in paraformaldehyde-fixed tissues. In: Methods in molecular biology, Vol 72, Neurotransmitter methods (Rayne RC, ed), pp 103-123. Totowa, NJ: Humana.

Pow DV, Barnett NL (1999) Changing patterns of spatial buffering of glutamate in developing rat retinae are mediated by the Müller cell glutamate transporter GLAST. Cell Tissue Res 297:57-66.

Pow DV, Barnett NL (2000) Developmental expression of excitatory amino acid transporter 5: a photoreceptor and bipolar cell glutamate transporter in rat retina. Neurosci Lett 280:21-24.

Rao VL, Dogan A, Bowen KK, Todd KG, Dempsey RJ (2001) Antisense knockdown of the glial glutamate transporter GLT-1 exacerbates hippocampal neuronal damage following traumatic injury to rat brain. Eur J Neurosci 13:119-128.
Robinson MB (1999) The family of sodium-dependent glutamate transporters: a focus on the GLT-1/EAAT2 subtype. Neurochem Int 33:479-491.

Rothstein JD, Martin LJ, Kuncl RW (1992) Decreased glutamate transport by the brain and spinal cord in amyotrophic lateral sclerosis. N Engl J Med 326:1464-1468.

Rothstein JD, Martin L, Levey AI, Dykes-Hoberg M, Jin L, Wu D, Nash N, Kuncl RW (1994) Localization of neuronal and glial glutamate transporters. Neuron 13:713-725.

Rothstein JD, Van Kammen M, Levey AI, Martin LJ, Kuncl RW (1995) Selective loss of glial glutamate transporter GLT-1 in amyotrophic lateral sclerosis. Ann Neurol 38:73-84.

Rothstein JD, Dykes-Hoberg M, Pardo CA, Bristol LA, Jin L, Kuncl RW, Kanai Y, Hediger MA, Wang Y, Schielke JP, Welty DF (1996) Knockout of glutamate transporters reveals a major role for astroglial transport in excitotoxicity and clearance of glutamate. Neuron 16:675-686.

Scott HL, Tannenberg AEG, Dodd PR (1995) Variant forms of neuronal glutamate transporter sites in Alzheimer disease cerebral cortex. J Neurochem 64:2193-2202. 